\title{
Erratum to: Predictors and prevalence of low bone mineral density in fully ambulatory persons with multiple sclerosis
}

Linn Hofsøy Steffensen • Svein Ivar Mellgren •

Margitta T. Kampman

Published online: 13 February 2010

(C) Springer-Verlag 2010

\section{Erratum to: J Neurol}

DOI 10.1007/s00415-009-5337-6

Figure 1: The figure was published incorrect and appears correctly here.

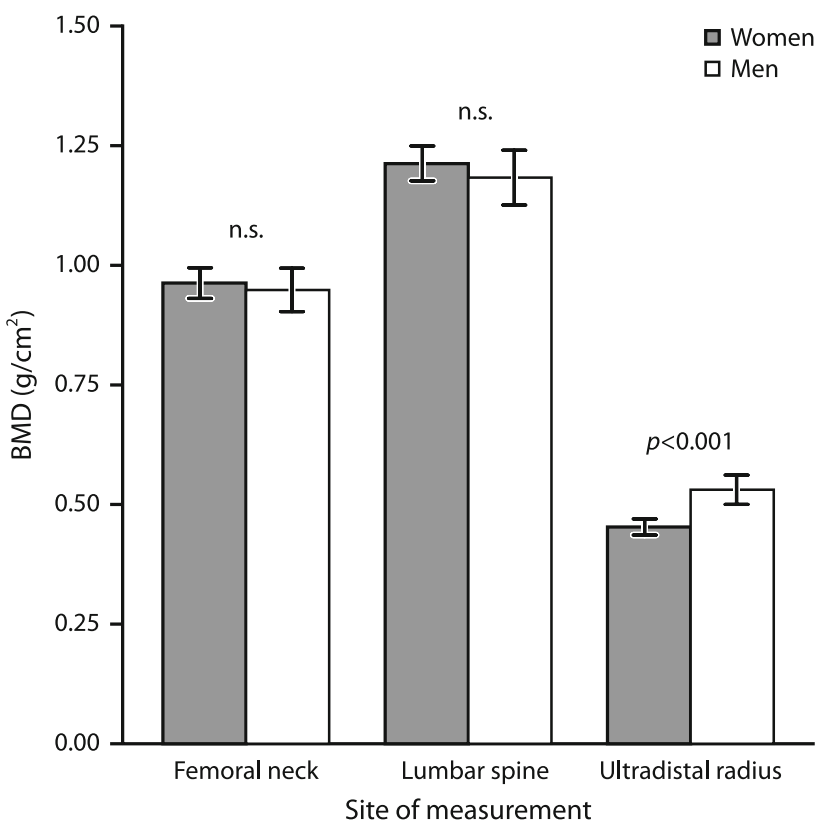

The online version of the original article can be found under doi:10.1007/s00415-009-5337-6.

L. H. Steffensen $(\bowtie)$ - S. I. Mellgren · M. T. Kampman Department of Neurology, University Hospital of North Norway, P.O. Box 33, 9038 Troms $\varnothing$, Norway

e-mail: linn.hofsoy.steffensen@unn.no

S. I. Mellgren

e-mail: svein.ivar.mellgren@unn.no

M. T. Kampman

e-mail: margitta.kampman@unn.no

L. H. Steffensen · S. I. Mellgren · M. T. Kampman

Department of Clinical Medicine, University of Troms $\varnothing$,

Troms $\varnothing$, Norway 
Table 2: Corrected table see below.

Table 2 Demographic, anthropometric, clinical, and nutritional data for the study participants

\begin{tabular}{|c|c|c|}
\hline & Women $(n=55)$ & Men $(n=25)$ \\
\hline Age, years, median (range) & $41(21-50)$ & $42(28-50)$ \\
\hline Lived north of the Arctic Circle the first 20 years of life & $84 \%$ & $68 \%$ \\
\hline BMI $\left(\mathrm{kg} / \mathrm{m}^{2}\right)$, median (range) & $25(18-41)$ & $27(20-39)$ \\
\hline Age at first symptom, years, median (range) & $29(15-47)$ & $31(18-43)$ \\
\hline Duration of MS from first symptom, years, median (range) & $9(2-26)$ & $7(1-27)$ \\
\hline EDSS, median (range) & $2.5(0-5)$ & $2(0-4.5)$ \\
\hline \multicolumn{3}{|l|}{ Intravenous methylprednisolone } \\
\hline Ever treated & $40 \%$ & $44 \%$ \\
\hline Cumulative dose, g, median (range) & $6(2-43)$ & $5(3-30)$ \\
\hline \multicolumn{3}{|l|}{ Disease modifying treatment } \\
\hline Beta-interferon & $42 \%$ & $52 \%$ \\
\hline Treatment duration, years, median (range) & $3(1-9)$ & $3(1-10)$ \\
\hline Glatiramer acetate & $6 \%$ & $0 \%$ \\
\hline \multicolumn{3}{|l|}{ Vitamin D status $[9,12]$ (serum 25(OH)D) } \\
\hline Deficient $(<25 \mathrm{nmol} / \mathrm{L})$ & $0 \%$ & $0 \%$ \\
\hline Insufficient (25-49 nmol/L) & $33 \%$ & $46 \%$ \\
\hline Marginal $(50-74 \mathrm{nmol} / \mathrm{L})$ & $53 \%$ & $33 \%$ \\
\hline Optimal $(\geq 75 \mathrm{nmol} / \mathrm{L})$ & $14 \%$ & $21 \%$ \\
\hline Median (range) (nmol/L) & $59(28-97)$ & $54(25-123)$ \\
\hline Ionised calcium, median (range) $(1.1-1.34 \mathrm{mmol} / \mathrm{L} \text { in serum })^{\mathrm{a}}$ & $1.21(1.13-1.28)$ & $1.23(1.11-1.31)$ \\
\hline PTH, median (range) $(1.1-6.8 \mathrm{pmol} / \mathrm{L} \text { in EDTA blood })^{\mathrm{a}}$ & $4.95(1.9-9.3)$ & $4.80(2.4-9.7)$ \\
\hline Vitamin D intake as recommended ( $\geq 7.5 \mu \mathrm{g}$ from diet and supplements) [9] & $53 \%$ & $64 \%$ \\
\hline Calcium intake as recommended ( $\geq 800 \mathrm{mg}$ from diet and supplements) [9] & $38 \%$ & $40 \%$ \\
\hline
\end{tabular}

Comparisons between men and women did not show statistically significant differences $B M I$ body mass index, EDSS expanded disability status scale

a Laboratory reference values 